GU J Sci, Part C,7(1): 123-140 (2019)

Gazi Üniversitesi
Fen Bilimleri Dergisi
PART C: TASARIM VE TEKNOLOJI
dergipark.gov.tr/http-gujsc-gazi-edu-tr

\title{
Klasik ve Çapraz Akı Dağılımına Sahip Döner Yapıdaki Anahtarlamalı Relüktans Motorların Performans Karşılaştırması
}

\author{
Nurettin ÜSTKOYUNCU ${ }^{1, *}$, Krishnan RAMU ${ }^{2}$ \\ ${ }^{I}$ Erciyes Üniversity, Engineering Faculty, The Department of Electrical \& Electronics Engineering, 38039, Melikgazi, Kayseri/TURKEY \\ ${ }^{2}$ Virginia Tech, The Bradley Department of Electrical \& Computer Engineering, 24061, Blacksburg/USA
}

\section{Makale Bilgisi \\ Başvuru:23/07/2018 \\ Düzeltme: $24 / 10 / 2018$}

Kabul:13/01/2019

\section{Anahtar Kelimeler}

Anahtarlamalı relüktans motor (ARM)

Çapraz akull motor

Tork yoğunluğu

\section{Keywords}

Switched reluctance motor (SRM)

Transverse flux motor

Torque density
$\ddot{O ̈ z}$

Yakın zaman içerisinde yapılan çalışmalarda, çapraz akı dağılımına sahip anahtarlamalı relüktans motorların (ÇARM), radyal akı dağılımına sahip klasik anahtarlamalı relüktans motorlar (KARM) ile kıyaslandığında yüksek güç ve tork yoğunluğuna sahip oldukları ifade edilmektedir. Sunulan çalışmada, KARM ile ÇARM'ler arasında kapsamlı bir karşılaştırma yapılmıştır. CCARM'lerin yapılandırılmasında gereksinim duyulan ek mekaniksel bileșenler, motora ait stator ve rotor bloklarının oluşturulmasında kullanılan malzemeler, ilgili malzemelerin manyetik karakteristikleri ve bu malzemelerin kullanılması sonucu motorun boyutları, hacim ve ağırlığında meydana gelen değişiklikler dikkate alınmak durumundadır. Dairesel sargı konfigürasyonu gibi farklı sargı olasılıkları performans açısından farklılıklar oluşturabilmektedir. Gerçekleştirilen çalışmada, adil bir karşılaştırma yapılabilmesi için KARM ve ÇARM yapıları eşit dış boyut, motor eksenel boyu ve manyetik akı yoğunluğu gibi kriterler ve bunun yanında benzer tork profilleri dikkate alınarak incelenmiştir. İncelenen makinaların performanslarının elde edilebilmesi için analitik hesaplamalar ile birlikte iki ve üç boyutlu sonlu elemanlar metotları (SEM) kullanılmıştır. Çalışmada elde edilen sonuçlar, KARM'lerin ÇARM'ler ile kıyaslandığında aynı ya da daha iyi performans sergilediğini açık bir şekilde göstermektedir. Bununla birlikte KARM'lerin çok daha kolay bir şekilde yapılandırılabilmesi, ilgili motorları ARM yapıları içerisinde avantajlı olan bir yapı olarak ortaya koymaktadır.

\section{A Performance Comparison of Conventional and Transverse Flux Rotating Switched Reluctance Motors}

\begin{abstract}
High power and torque densities have been claimed for transverse flux structures over the conventional (radial flux) switched reluctance machine (CSRM) structures in recent publications. A comprehensive comparison between the transverse SRMs (TSRM) and CSRMs requires inclusion of the specific constructional requirements of the TSRM. Then it must take into account the back irons of the stator and rotor, the material for them and their magnetic characteristics, and their resulting impact on the outer machine dimensions, weight and volume. Performance differentiation that can accrue as a result of different winding possibilities such as hoop (circular) and concentric windings on the TSRM are also considered for the comparison. For a fair comparison of the two types of the SRMs, equal outer dimensions, stack length and magnetic flux density are assumed. In addition, similar torque profiles are also considered. Both analytical and 2D and 3D finite element methods (FEM) are employed in this research to determine the performance of the machines. The research results clearly indicate that CSRMs match or exceed the performance of the TSRMs. In combination with this fact that CSRMs are simpler to construct will make them the choice structure for the switched reluctance motor (SRM) kind.
\end{abstract}




\section{GIRISŞ (INTRODUCTION)}

Anahtarlamalı relüktans motorlar (ARM) sahip oldukları yüksek verim, sağlam yapı, sargı ya da mıknatıs içermeyen düşük maliyetli rotorları ve yüksek hata toleransları ile endüstriyel uygulamalar için oldukça iyi alternatiflerdendir [1-7]. ARM'leri de içeren klasik elektrik makinalarının stator ve rotor kutuplarında akı radyal yönlü iken stator ve rotor arka demirlerinde ise dairesel yönlüdür. Çapraz akı dağılımına sahip anahtarlamalı relüktans motorları (ÇARM) da içeren çapraz akı dağılımlı makinelerde ise stator ve rotor kutuplarında akı radyal yönlü iken stator ve rotor arka demirlerinde ise eksenel yön söz konusudur. Literatürde yapılan çalışmalarda çapraz akı dağılımına sahip doğrusal ve döner yapıdaki ARM'lerin, KARM'ler ile kıyaslandığında daha yüksek kuvvet/tork ve güç yoğunluklarına sahip olduğu vurgulanmaktadır [8-15]. Aynı zamanda dairesel sargıya sahip ÇARM'lerin bu konuda ciddi avantaja sahip olduğu da belirtilmektedir [16-19]. Ancak ÇARM'lerin bazı yapısal problemlere ve boyutsal kısıtlamalara sahip olduğu da bilinmektedir [16-20]. Bu sıkıntılara ilişkin yapılan bir çalışmada klasik yapıdaki doğrusal hareket gerçekleştiren ARM'lerin (DARM) çapraz akı dağılımına sahip DARM'ler ile kıyaslandığında daha uygun bir çözüm olduğu gösterilmiştir [21]. Bununla birlikte, ÇARM'lerin arka demirlerinin neden olduğu yapısal sınırlamalar ve bunun tork yoğunluğuna olan etkileri ile ilgili olarak önceki çalışmalarda yeteri kadar bilgi bulunmamaktadır. Bu çalışmada, ÇARM'lerin farklı özellikleri de dikkate alınarak kapsamlı bir karşılaştırma analizi yapılmıştır.

Yapılan çalışmada, literatürde yer almakta olan neredeyse tüm ÇARM yapıları dikkate alınmış ve bu yapılar ile eşdeğer nitelikteki KARM yapıları karşılaştırılmıştır. Karşılaştırmaların adil olarak yapılabilmesi adına öncelikle eşit maksimum ak1 yoğunluğu ve ardından da benzer tork profilleri için farklı açılardan değerlendirmeler yapılmış ve elde edilen sonuçlar detaylı bir şekilde sunulmuştur. Analiz işlemleri, performans eşitliklerini temel alan analitik yöntem yanında iki ve üç boyutlu sonlu elemanlar analizi (SEA) temel alınarak gerçekleştirilmiştir. KARM'ler için iki boyutlu SEA (2B-SEA) kullanımı yeterli iken eksenel baskınlığı nedeni ile ÇARM'lerde üç boyutlu SEA (3B-SEA) kullanılmıştır. KARM'lere ait iki ve üç boyutlu SEA sonuçları arasındaki farkın önemli boyutlarda olmadığı da çalışmada gösterilmiştir.

Yapılan çalışmada, incelenen farklı ÇARM yapılarına ilişkin detaylar Bölüm 2'de verilmiştir. Çalışmada yer alan çapraz akı dağılımına sahip anahtarlamalı relüktans makineleri ve temel boyutsal ilişkileri ile karşılaştırma amaçlı olarak dikkate alınan KARM'ler Bölüm 3'te incelenmiştir. Bölüm 4'te performans eşitliklerinin türetilmesine ve karşılaştırma sonuçlarına yer verilmiştir. ÇARM'lerin arka demir yapıları ile bu yapıların performansa olan etkileri KARM'ler ile karşılaştırmalı olarak Bölüm 5'te sunulmuştur. Çalışmada elde edilen sonuçlar ise Bölüm 6'da özetlenmiştir.

\section{2. ÇARM YAPILARI (TSRM STRUCTURES)}

Çapraz akı dağılımına sahip elektrik makinanaları, radyal ve eksenel akı dağılımına sahip elektrik makinalarının ortak bir nesli olarak gösterilebilir. Burada çalışmada kullanılan beş farklı ÇARM yapısı kısaca özetlemiştir.

\subsection{Tip 1A ve Tip 1B ÇARM'ler (Type 1A and Type 1B TSRMs)}

Tip 1A ÇARM'ler stator ve rotorlarında C şeklindeki saçlara sahiptirler ve Şekil 1(a)'da gösterildiği üzere bu stator bileşenleri dairesel bir eksende yer almaktadır. Stator sargısı da daireseldir ve stator yarığına yerleştirilmiştir. Şekil 1(a), Tip 1A ÇARM'ye ait bir fazı göstermektedir ve çok fazlı motor, peşi sıra eksenel olarak bu fazların bir araya getirilmesi ile oluşturulmaktadır.

Bu makinanın sahip olduğu en büyük mekaniksel problem, C şeklindeki çekirdeğe sahip stator ve rotor bileşenlerinin bir arada tutulmasıdır. Bununla birlikte basit sargı yapısı ile stator ve rotor için düşük miktarda silisli saç kullanımı ilgili makinanın avantajlarındandır. Tip 1B ÇARM'de ise rotor saçlarının I şeklinde olması haricinde Şekil 1(b)'den görülebileceği üzere başka bir fark bulunmamaktadır. 


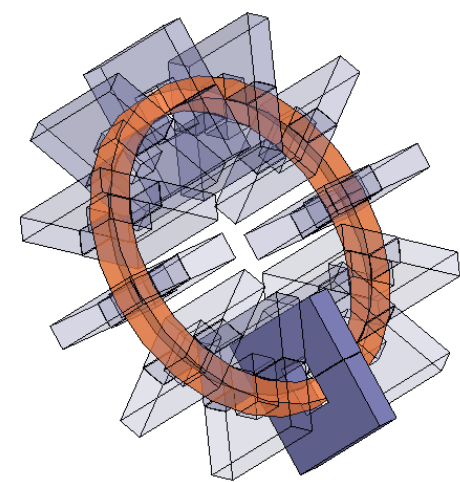

(a)

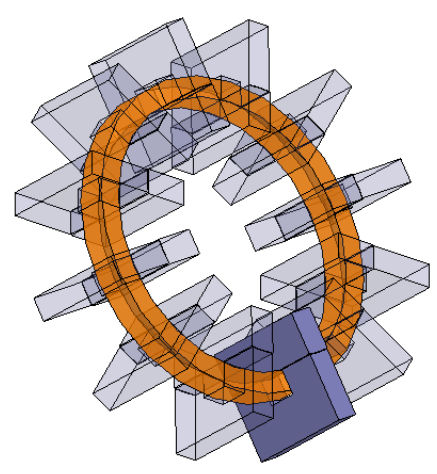

(b)

Şekil 1. (a) Tip 1A, (b) Tip IB ÇARM yapıları ((a) Type 1A, (b) Type 1B TSRM structures)

\subsection{Tip 2A ve Tip 2B ÇARM'ler (Type 2A and Type 2B TSRMs)}

Tip 2A ve Tip 2B ÇARM yapıları, sargı yapısı haricinde sırasıyla Tip 1A ve Tip 1B ÇARM yapılarıyla aynıdır. Tip 2A ve Tip 2B ÇARM'lerde Şekil 2'den görülebileceği üzere her bir stator kutbunun kendi sargısı bulunmakta olup bu sargılar $\mathrm{C}$ şeklindeki stator bileşeninin arka demirinde yer almaktadır. Çok fazlı motor, Tip 1A ve Tip 1B motor yapılarında ifade edildiği üzere gerçekleştirilebileceği gibi eşit sayıda olmayan stator ve rotor kutup kombinasyonları ile KARM'lerde olduğu gibi de ortaya konabilir. Genel olarak, Tip 2A ve Tip 2B motorların üretim zorluğu Tip 1A ve Tip 1B ÇARM'ler ile benzerdir.

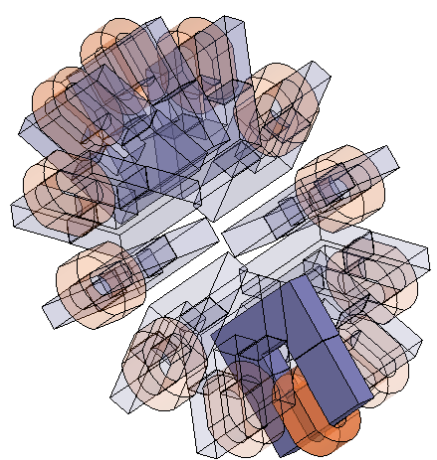

(a)

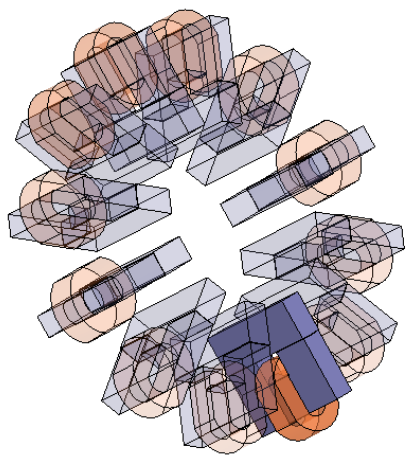

(b)

Şekil 2. (a) Tip 2A, (b) Tip 2B ÇARM yapıları ((a) Type 2A, (b) Type 2B TSRM structures)

\subsection{Tip 3A ve Tip 3B ÇARM'ler (Type 3A and Type 3B TSRMs)}

Tip 3A ve Tip 3B ÇARM yapıları, sırasıyla Tip 2A ve Tip 2B ÇARM yapılarında yer alan C şekildeki stator çekirdeklerinin E şeklindeki çekirdeklerle yer değiştirmesi haricinde aynıdır. Şekil 3'ten görülebileceği üzere Tip 3A ve Tip 3B ÇARM rotorları sırasıyla E ve I şeklindeki çekirdeklere sahiptir. Eğer sarg1, E şeklindeki stator çekirdeğinin orta bacağına yerleştirilecek olursa Tip $2 \mathrm{~A}$ ve Tip 2B ÇARM'den farklı olarak sargı stator bileşenlerinin dışına taşmamaktadır. Tip 3A ve Tip 3B ÇARM'lerin mekaniksel yapılandırma problemleri daha önce sözü edilen diğer ÇARM'ler ile benzerdir. 


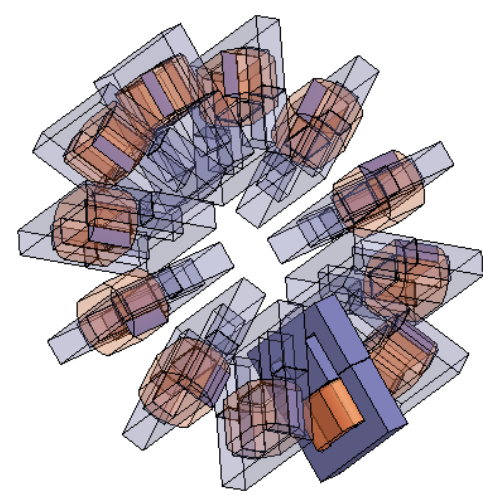

(a)

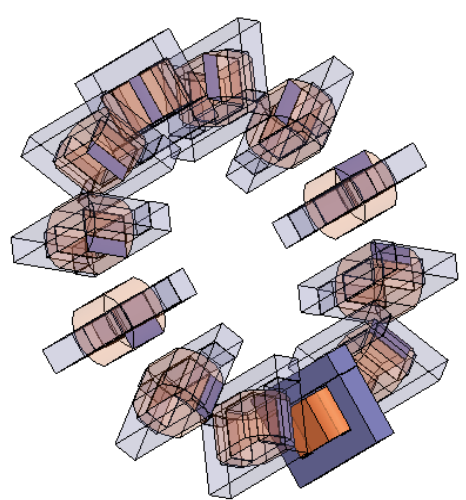

(b)

Şekil 3. (a) Tip 3A, (b) Tip 3B ÇARM yapıları ((a) Type 3A, (b) Type 3B TSRM structures)

\subsection{Tip 4A ve Tip 4B ÇARM'ler (Type 4A and Type 4B TSRMs)}

E şeklideki stator çekirdeklerine sahip ÇARM'ler gerek dairesel sargı gerekse de her bir stator çekirdeği için ayrı bir sargı kullanılarak gerçekleştirilebilmektedir. Dolayısıyla Tip 4A ve Tip 4B ÇARM'ler sahip oldukları sargı yapıları haricinde Tip 3A ve Tip 3B ÇARM'ler ile çok benzerdir. Şekil 4'ten görülebileceği üzere Tip 4A ve Tip 4B ÇARM'ler, stator çekirdeklerinin ayrıkları ve arka demirleri içerisinde yer alan ikişer adet dairesel sargıya sahiptir.

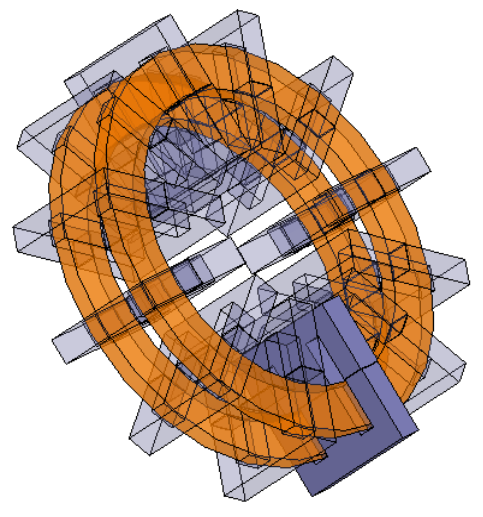

(a)

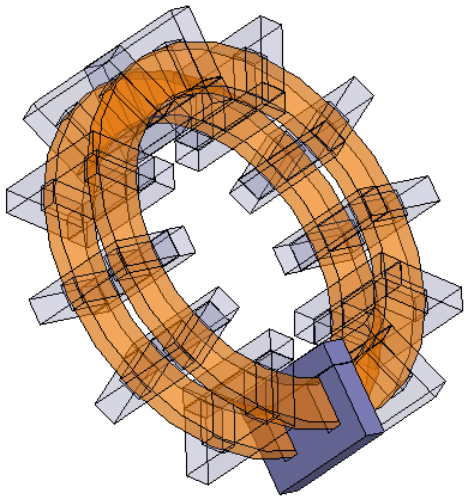

(b)

Şekil 4. (a) Tip 4A, (b) Tip 4B ÇARM yapıları ((a) Type 4A, (b) Type 4B TSRM structures)

\subsection{Tip 5 ÇARM (Type 5 TSRM)}

Şekil 5'ten görülebileceği üzere Tip 5 ÇARM'de stator bloğu, saç plakalarından meydana gelen halka şeklindeki iki stator bileşeninin yan yana getirilmesi ile oluşmakta ve dairesel olan stator sargisı da bu iki stator halkası arasına yerleştirilmektedir. Eksenel akı dağılımının sağlanabilmesi için ise bu iki stator halkasının arka demiri, tozlandırılmış demir malzemeden üretilmiş bir yapı ile sağlanmaktadır. Benzer yapı rotor bloğu için de geçerlidir. Gerçekte Tip 1A ÇARM'nin yapısını andıran bu motor yapısı diğer ÇARM'ler ile kıyaslandığında daha düşük üretim zorluğuna sahiptir. 


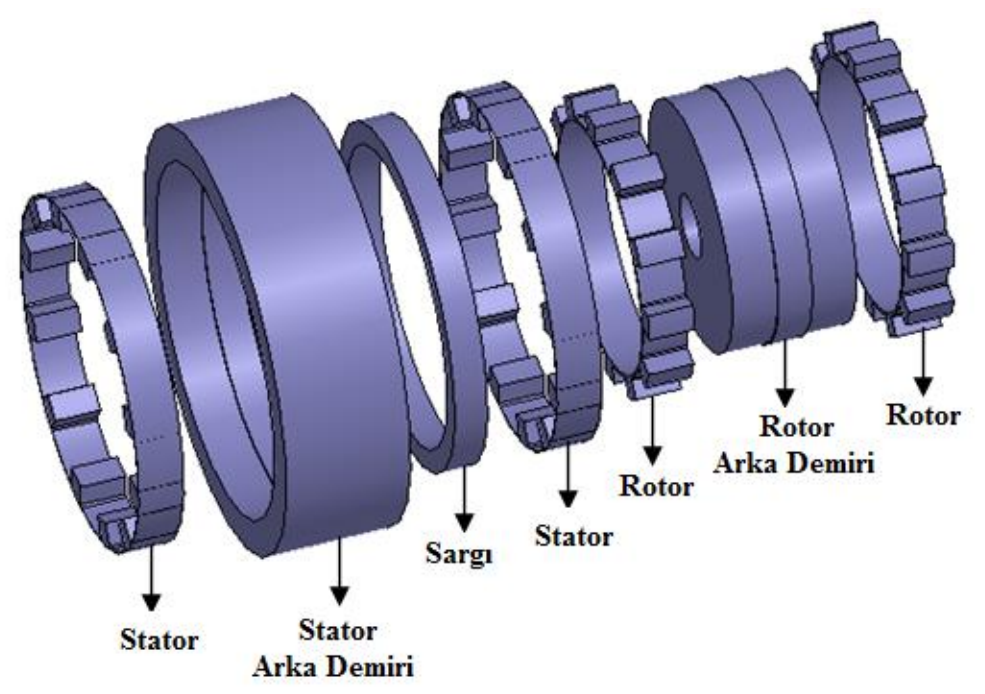

Şekil 5. 12/12 yapıdaki Tip 5 ÇARM'nin tek fazına ait detayl görünüm (Detailed appearance of one phase of the Type 5 12/12 TFSRM)

\section{3. ÇALIŞMADA YER ALAN MAKİNALAR VE BOYUTLARI ÍLE ÍLGILİ HUSUSLAR (MACHINES FOR THE STUDY AND THEIR DIMENSIONAL CONSIDERATIONS)}

Bu çalışmada yer alan makinaların boyutlandırılmasında Tip 5 ÇARM temel alınmıştır. Tip 5 ÇARM yapısının rotor ve stator blokları için tozlandırılmış demirden yapılan arka demire gereksinim duyması ve Şekil 6'dan da görülebileceği üzere bu amaçla kullanılan malzemenin (Mu-Metal) manyetik akı yoğunluğunun saç malzemenin (Steel 1008) akı yoğunluğu ile kıyaslandığında daha düşük değerlerde olması Tip 5 ÇARM'nin boyutlarını artırmaktadır.

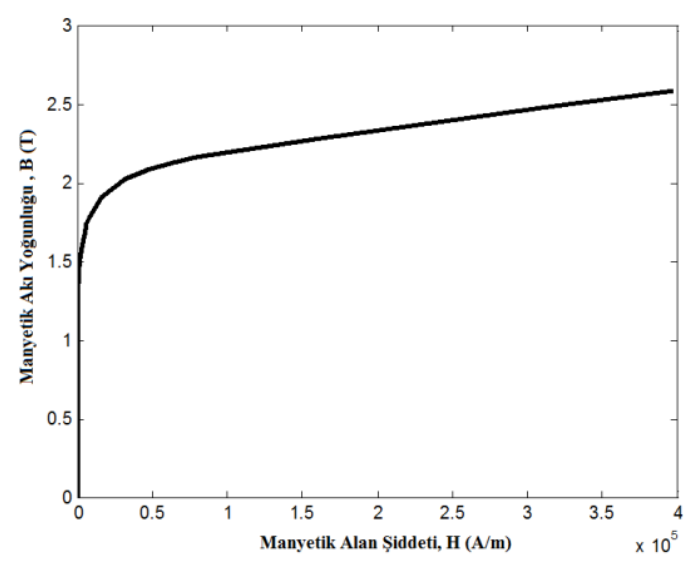

(a)

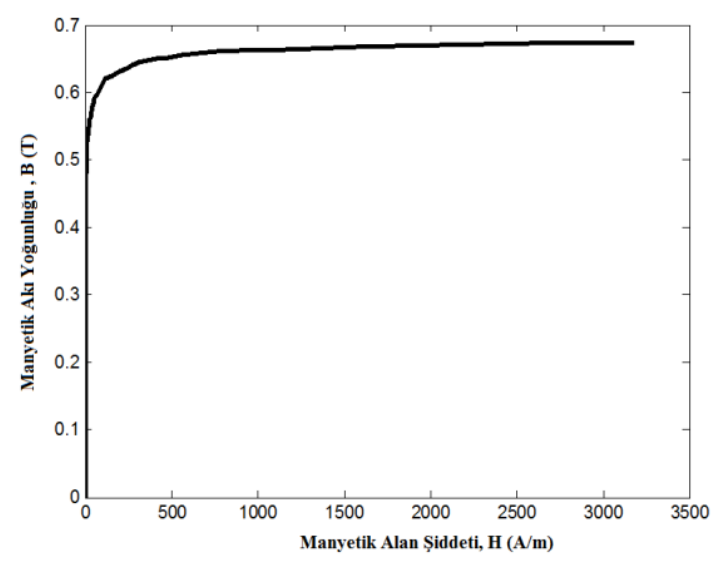

(b)

Şekil 6. Çalışmada kullanılan malzemelerin B-H karakteristiği (a) Steel 1008 (b) Mu-Metal (B-H characteristics of the used materials (a) Steel 1008 (b) Mu-Metal)

Tozlandırılmış demir malzemenin kullanıldığı stator ve rotor blokları ile ilgili bazı temel büyüklüklerin türetilmesi üzerinde durulursa, bir ARM'nin stator kutup alanı Eş. 1 ile verildiği gibidir.

$$
A_{s}=l_{s} w_{s}
$$

Burada $l_{s}$ ve $w_{s}$, sırasıyla stator kutup uzunluğu ve stator kutbunun genişliğini ifade etmektedir. Aktif stator tozlandırılmış demir malzeme kutup alanı ise Eş. 2'de verildiği gibidir. 


$$
A_{s p i}=l_{s p i} w_{s p i}
$$

Eş. 2'de yer alan $l_{s p i}$ ve $w_{s p i}$, sırasıyla tozlandırılmış demir malzemenin bir stator kutbu için aktif uzunluğunu (kalınlığını) ve genişliğini ifade etmektedir. Stator ve rotor kutuplarının üretildiği manyetik saç ve tozlandırılmış demir malzemenin eşit akı taşıdığı düşünüldügünde,

$$
\phi_{s}=\phi_{s p i}
$$

eşitliği yazılabilir. Eş. 3'te $\phi_{s}$ ve $\phi_{s p i}$, manyetik saç ve tozlandırılmış demir malzemenin manyetik akı değerini göstermektedir. Manyetik akı, manyetik akı yoğunluğu ve kesit alan olarak Eş. 4'te verildiği gibi ifade edilebilir.

$$
\phi=B A
$$

Burada $B$ manyetik akı yoğunluğu ve $A$ ise etkin kesit alandır. Eş. 1 ve 4 kullanılarak statora ait tozlandırılmış demir malzemenin kalınlığı Eş. 5'teki gibi yazılabilir.

$$
l_{s p i}=\left(\frac{B_{s}}{B_{s p i}}\right) \frac{l_{s} w_{s}}{w_{s p i}}
$$

Eş. 5'te $B_{s}$ ve $B_{s p i}$ sırasıyla manyetik saç ve stator tozlandırılmış demir malzemenin diz noktalarındaki manyetik akı yoğunluğu değerleridir. Statora ait tozlandırılmış demir malzemenin bir stator kutbu için aktif genişliği ise

$$
w_{s p i}=k_{s} w_{s}
$$

şeklinde ifade edilebilir. Eş. 6 'da $k_{s}$, stator tozlandırılmış demir malzemeye ait katsayı değeri olup değeri Eş.7'de verildiği gibidir.

$$
k_{s}>1
$$

Eş. 5 ve 6 kullanılarak statora ait tozlandırılmış demir malzemenin kalınlığı Eş. 8'de verildiği gibi düzenlenebilir.

$$
l_{s p i}=\left(\frac{B_{s}}{B_{s p i}}\right) \frac{l_{s}}{k_{s}}
$$

Sonuç olarak, statora ait tozlandırılmış demir malzemenin yarıçapı Eş. 9'da verildiği gibi elde edilmiş olur.

$$
r_{s p i}=r_{\text {sout }}+l_{s p i}
$$

Benzer şekilde rotora ait tozlandırılmış demir malzemenin kalınlığı Eş. 10'da verildiği gibi ifade edilebilir.

$$
l_{r p i}=\left(\frac{B_{r}}{B_{r p i}}\right) \frac{l_{r}}{k_{r}}
$$

Eş. 10 'da $B_{r}$ ve $B_{r p i}$, sırasıyla rotora ait manyetik saç ve tozlandırılmış demir malzeme için diz noktalarındaki manyetik akı yoğunluğu değerlerini ifade etmektedir. $l_{r}$, rotor kutbunun eksenel boyu ve $k_{r}$ ise rotor tozlandırılmış demir malzeme için katsayı değeridir. Rotora ait tozlandırılmış demir malzemenin yarıçapı ise Eş. 11'de verildiği gibi yazılabilir.

$$
r_{r p i}=r_{s h}+l_{r p i}
$$

Eş. 11 'de $r_{s h}$, şaft yarıçapıdır.

Yapılan çalışmada, sözü edilen ÇARM'ler ile adil bir karşılaştırma yapılabilmesi adına Tip A ve Tip B olarak verilen iki farklı KARM yapısı dikkate alınmıştır. Tip A KARM, ÇARM'lerle aynı rotor dış çapına 
sahipken, stator dış çapı ÇARM'lerden daha düşüktür. Tip B KARM ise Tip 5 ÇARM ile aynı stator dış çapına sahiptir. Ancak, Tip B KARM'nin rotor dış çapı Tip 5 ÇARM dikkate alınarak boyutlandırılmış olan ÇARM'lerin rotor dış çapından daha büyüktür. Çalışmada incelenen tüm makinalara ait bazı temel boyutlar Tablo 1'de verilmiştir.

Tablo 1. Makina boyutlarl (Machine dimensions)

\begin{tabular}{|c|c|c|c|c|c|c|c|c|}
\hline \multirow{2}{*}{ KARM Özellikleri } & \multicolumn{2}{|c|}{ 12/8 KARM } & \multicolumn{2}{|c|}{ 18/12 KARM } & \multirow{2}{*}{$\begin{array}{c}\text { 8/8 } \\
\text { ÇARM } \\
\text { Tip } 5\end{array}$} & \multirow{2}{*}{$\begin{array}{c}12 / 12 \\
\text { ÇARM } \\
\text { Tip } 5\end{array}$} & \multirow{2}{*}{$\begin{array}{c}8 / 8 \text { ÇARM } \\
\text { Tipleri } \\
\text { 1A-1B, 2A- } \\
\text { 2B, 3A-3B } \\
\text { 4A-4B }\end{array}$} & \multirow{2}{*}{$\begin{array}{c}\text { 12/12 ÇARM } \\
\text { Tipleri } \\
\text { 1A-1B, 2A- } \\
\text { 2B, } \\
\text { 3A-3B, 4A- } \\
\text { 4B }\end{array}$} \\
\hline & Tip A & Tip B & Tip A & Tip B & & & & \\
\hline $\begin{array}{l}\begin{array}{l}\text { Eksenel Uzunluk } \\
(\mathrm{mm})\end{array}\end{array}$ & 165 & 165 & 165 & 165 & 165 & 165 & 165 & 165 \\
\hline $\begin{array}{l}\text { Stator D1ş Çap1 } \\
(\mathrm{mm})\end{array}$ & 170 & 185 & 170 & 185 & 154 & 154 & 194 & 194 \\
\hline $\begin{array}{l}\text { Stator Tozlandırilmış Demir Malzeme } \\
\text { Dis Capı }(\mathrm{mm})\end{array}$ & & & & & 185 & 185 & & \\
\hline $\begin{array}{l}\text { Boyunduruk Kalınlığ } 1 \\
(\mathrm{~mm})\end{array}$ & 9 & 10 & 9 & 10 & 15,5 & 15,5 & 20 & 20 \\
\hline $\begin{array}{l}\text { Rotor Tozlandırilmış Demir Malzeme } \\
\text { Dis Cap } 1(\mathrm{~mm})\end{array}$ & & & & & 109,5 & 109,5 & & \\
\hline $\begin{array}{l}\text { Rotor Tozlandırilmış Demir Malzeme } \\
\text { Kalınlığ }(\mathrm{mm})\end{array}$ & & & & & 40,25 & 40,25 & & \\
\hline $\begin{array}{l}\text { Rotor D1ş Çap1 } \\
(\mathrm{mm})\end{array}$ & 130 & 145 & 130 & 145 & 130 & 130 & 130 & 130 \\
\hline $\begin{array}{l}\text { Hava Aralığ } 1 \\
(\mathrm{~mm})\end{array}$ & 0,25 & 0,25 & 0,25 & 0,25 & 0,25 & 0,25 & 0,25 & 0,25 \\
\hline $\begin{array}{l}\text { Rotor İç Çap1 } \\
(\mathrm{mm})\end{array}$ & 111,5 & 126,5 & 111,5 & 126,5 & 111,5 & 111,5 & 111,5 & 111,5 \\
\hline Stator Kutup Sayısı & 12 & 12 & 18 & 18 & 8 & 12 & 8 & 12 \\
\hline Rotor Kutup Sayis1 & 8 & 8 & 12 & 12 & 8 & 12 & 8 & 12 \\
\hline $\begin{array}{l}\text { Stator Kutup Açısı } \\
\left({ }^{\circ}\right)\end{array}$ & 15 & 15 & 10 & 10 & 15 & 10 & 15 & 10 \\
\hline $\begin{array}{l}\text { Rotor Kutup Açısı } \\
\left({ }^{\circ}\right)\end{array}$ & 16 & 16 & 10,75 & 10,75 & 16 & 10,75 & 16 & 10,75 \\
\hline
\end{tabular}

Bu çalışmada KARM'lerin analizi için 2B-SEA kullanılmıştır. Tip A KARM için iki ve üç boyutlu SEA kullanılarak aynı şartlar altında elde edilen sonuçlar Tablo 2'de karşılaştırılmıştır. Tablo 2'ye bakıldığı zaman 2B-SEA ile elde edilen ortalama tork değerinin 3B-SEA ile elde edilenden yüksek olduğu görülmektedir. Bununla birlikte iki yöntem arasındaki maksimum fark \% 3.31 olarak ortaya çıkmaktadır. Dolayısıyla çalışmada KARM'lerin analizinde 2B-SEA'nın kullanılması uygun görülmüştür.

Tablo 2. Aynı şartlarda elde edilen $2 B$ ve $3 B$ SEA sonuçlarının karşılaştırılması (Comparing $2 D$ and $3 D$ FEA results obtained with the same conditions)

\begin{tabular}{||c||c|c|c||}
\hline \multicolumn{1}{|c|}{ Özellikler } & \multicolumn{3}{c|}{$\begin{array}{c}\text { 12/8 KARM } \\
\text { Tip A }\end{array}$} \\
& 2B-SEA & 3B-SEA & Yüzdesel Fark \\
\hline \hline \multirow{3}{*}{ Ortalama Tork (Nm) } & 2,95 & 2,86 & 3,05 \\
\cline { 2 - 5 } & & \multicolumn{3}{c|}{$\begin{array}{c}18 / 12 \text { KARM } \\
\text { Tip A }\end{array}$} \\
\cline { 2 - 5 } & 5,14 & 4,97 & 3,31 \\
\hline
\end{tabular}




\section{4. ÖN ANALIZ (PRELIMINARY ANALYSIS)}

Bu kısımda temel prensiplerden türetilmiş olan ve klasik ARM'ler ile çapraz akı dağılımına sahip ARM'ler arasındaki tork oranını veren ifadelere yer verilmiştir. Makineler için manyetik olarak doğrusal çalışma bölgesi dikkate alındığında elektromanyetik tork $T_{e}$, ko-enerji ile bağlantılı olarak Eş. 12 'de verildiği gibi ifade edilebilir.

$$
T_{e}=\frac{d W^{\prime}}{d \theta}
$$

Burada, $\theta$ rotor konumunu ifade etmektedir. Eş. 12 'de yer alan ko-enerji $W^{\prime}$ ise halkalanma akısı $\lambda$ ve akım $i$ kullanılarak,

$$
W^{\prime}=\int_{0}^{i} \lambda(i, \theta) d i
$$

şeklinde ifade edilebilir.

$$
\lambda(\mathrm{i}, \theta)=\mathrm{L}(\mathrm{i}, \theta) \mathrm{i}
$$

Eş. 14'te $\mathrm{L}$, akım ve rotor konumunun bir fonksiyonu olarak indüktansı ifade etmektedir. Bu çalışmada ortalanmış konumdaki indüktans ve etkileri daha kolay bir şekilde eşitliklerin elde edilebilmesi adına ihmal edilmiştir. Çakışı konumdaki indüktans $\mathrm{L}_{\mathrm{a}}$ ifadesi, motor boyutları ve sarım sayısı ile Eş. 15 'te verildiği gibidir.

$$
L_{a}=\frac{N^{2}}{\mathfrak{R}}=\frac{P_{s}}{q}\left\{\frac{N^{2}}{\left(l_{g} / A \mu_{0}\right)}\right\}
$$

Burada $P_{s}$ stator kutup sayısını, $q$ faz sayısını, $N$ kutup başına sarım sayısını, $l_{g}$ stator ve rotor kutbu arasındaki hava aralığını, $A$ etkin kesit alanını, $\mu_{0}$ hava aralığındaki manyetik geçirgenliğini ve $\mathfrak{R}$ ise manyetik akı yolundaki relüktans değerini göstermektedir. Eş. 12 ve 15 dikkate alındığında elektromanyetik tork değeri makine parametreleri cinsinden Eş. 16'da verildiği gibi ifade edilebilir.

$$
T_{e}=\left(\frac{\mu_{0} P_{s} A}{2 q l_{g}}\right) \frac{\left(N^{2} i^{2}\right)}{d \theta}
$$

Burada $d \theta$, Eş. 17 'de verildiği üzere çakışı rotor konumu $\theta_{a}$ ve ortalanmış rotor konumu $\theta_{u}$ arasındaki radyan cinsinden farkı ifade etmektedir.

$$
d \theta=\theta_{a}-\theta_{u}=\frac{2 \pi}{q P_{r}}
$$

Burada $P_{r}$ rotor kutup sayısını ifade etmektedir ve faz sayısı ile stator kutup sayısı cinsinden Eş. 18 'de verildiği gibi yazılabilir.

$$
P_{r}=\frac{q-1}{q} P_{s}
$$

Eş. 16, 17 ve 18 dikkate alınarak tork, Eş. 19'da verildiği gibi ifade edilebilir.

$$
T_{e}=\frac{\mu_{0}}{4 \pi}\left(\frac{P_{s} P_{r} A}{l_{g}}\right)(N i)^{2}=\frac{\mu_{0}}{4 \pi} \frac{q}{q-1}\left(\frac{A}{l_{g}}\right)\left(P_{r} N i\right)^{2}
$$

Eş. 19, KARM'ye ait elektromanyetik tork $T_{e_{c}}$ ve ÇARM'ye ait elektromanyetik tork $T_{e t}$ oranının elde edilmesi için kullanıldığında;

$$
\frac{T_{e_{c}}}{T_{e t}}=\frac{A_{c} P_{r c}{ }^{2} N_{c}^{2}}{A_{t} P_{r t}^{2} N_{t}^{2}}
$$


Eş. 20 ifadesi elde edilir. Burada semboller ile birlikte kullanılan c ve $\mathrm{t}$ alt indisleri bu sembollerin sırasıyla klasik ve çapraz akı dağılımına sahip makinaya ait olduğunu göstermektedir. Burada eşit nitelikteki güç sistemleri ve hava aralığına bağlı üretim sıkıntıları açısından eşdeğer durumların değerlendirilebilmesi adına tüm ARM'ler için akım ve hava aralığının aynı olduğu varsayılmıştır.

ÇARM'lerin çakışık konumdaki indüktansı Eş. 21 kullanılarak hesaplanabilir.

$$
L_{a}=\frac{P_{s} N B A}{i}
$$

Manyetik akı yoğunluğunun maksimum değeri dikkate alınıp tasarımlar gerçekleştirildiğinde 8/8 Tip 5 ÇARM ve 12/8 Tip A KARM ile 12/ 12 Tip 5 ÇARM ile 18/12 Tip A KARM motor yapıları için Eş. 20, 22 ve 23'ün kullanılması ile yapılan hesaplamalarda klasik yapıdaki ARM'lerin çapraz akı dağılımına sahip ARM'lere göre iki kat daha fazla tork üretebilme potansiyeline sahip olduğu görülmektedir. Bu durumun sebebi, ilgili kriterler altında KARM'lerin ÇARM'lere kıyasla 8 kat daha fazla etkin kutup alanına sahip olmasıdır.

$$
\begin{aligned}
& \frac{T_{e_{c}}}{T_{e t}}=\frac{A_{c} P_{r c}{ }^{2} N_{c}{ }^{2}}{A_{t} P_{r t}{ }^{2} N_{t}{ }^{2}} \cong \frac{A_{C} P_{r t}{ }^{2} 72^{2}}{1 / 8 A_{C} P_{r t}{ }^{2} 144^{2}} \cong 2 \\
& \frac{T_{e_{c}}}{T_{e_{t}}}=\frac{A_{c} P_{r c}{ }^{2} N_{c}{ }^{2}}{A_{t} P_{r t}{ }^{2} N_{t}{ }^{2}} \cong \frac{A_{C} P_{r t}{ }^{2} 50^{2}}{1 / 8 A_{C} P_{r t}{ }^{2} 100^{2}} \cong 2
\end{aligned}
$$

Aynı sonuçlar 8/8 Tip 1A ÇARM ve 12/8 Tip B KARM ile 12/ 12 Tip 1A ÇARM ve 18/12 Tip B KARM için de geçerlidir. Manyetik akı yoğunluğunun maksimum değeri dikkate alınarak yapılan tasarımlar için SEA sonunda elde edilen tork ve stator kutbu ortalama manyetik akı yoğunluğu karakteristikleri sırasıyla Şekil 7 ve 8 'de gösterilmiştir. Şekil 7 ve 8'den görülebileceği üzere motorlara ait stator kutbuna ait akı yoğunluğu profilleri benzer olmasına karşın KARM'lerin üretmiş olduğu tork değerleri, ÇARM'lerin üretmiş olduğu tork değerlerine kıyasla çok daha yüksek olup arada yaklaşık olarak iki katlık bir fark vardır. 18/12 KARM'ler ile 12/12 ÇARM'ler için elde edilen sonuçlar da benzer olduğu için ilgili motorlara ait sonuçlar sadelik sağlanabilmesi için adına çalışmada verilmemiştir.

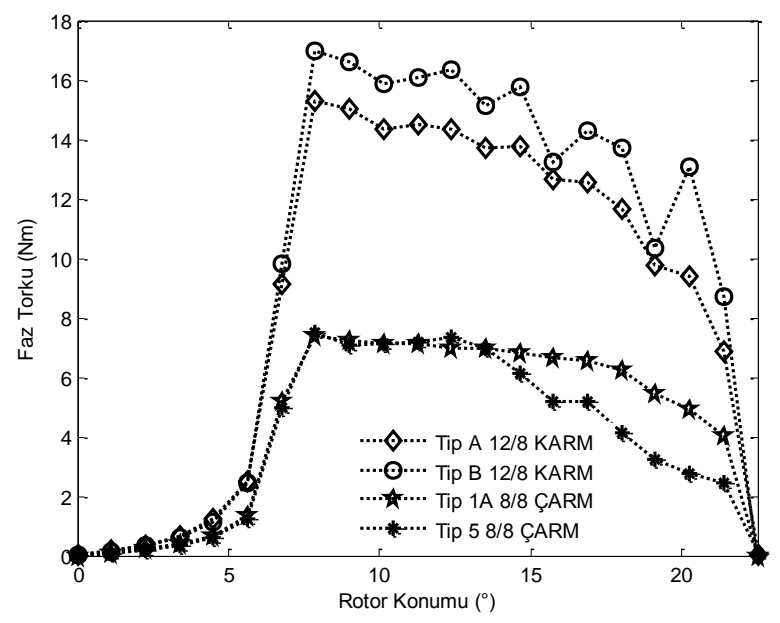

Şekil 7. Manyetik akı yoğunluğunun maksimum değerine göre tasarımı yapılan farklı yapıdaki 12/8 KARM ve 8/8 ÇARM'ler için rotor konumuna karşlllk faz torku (Phase torque versus rotor position for various 12/8 CSRMs and 8/8 TSRMs designed to obtain maximum flux density ) 


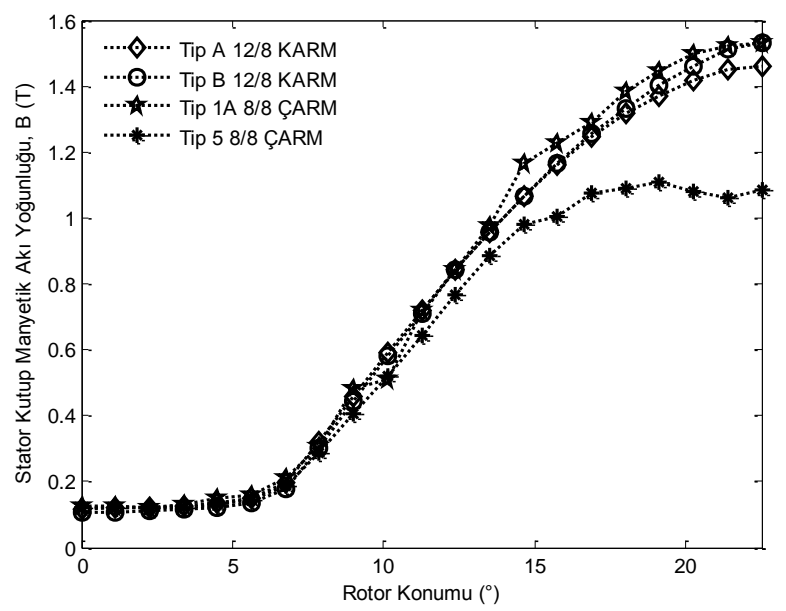

Şekil 8. Manyetik akı yoğunluğunun maksimum değerine göre tasarımı yapılan farklı yapıdaki 12/8 KARM ve 8/8 ÇARM'ler için rotor konumuna karşıllk stator kutbu akı yoğunluğu (Stator pole flux density versus rotor position for various 12/8 CSRMs and 8/8 TSRMs designed to obtain maximum flux density)

8/8 ÇARM yapıları için maksimum sarım sayısı stator yarık hacmi tarafından sınırlanır ve kutup başına 144'tür. Aynı zamanda 18/12 KARM de aynı sayıda sarım yapılabilmesi için 12/8 KARM'nin sahip olduğu yarık hacmine sahip değildir. Benzer şekilde 12/12 ÇARM de 8/8 ÇARM ile kıyaslandı̆̆ında daha az sarım sayısına sahiptir.

8/8 ÇARM ve 12/8 KARM'ye ait faz akımları ya da 12/12 ÇARM ve 18/12 KARM'ye ait faz akımlarının eşit olduğu düşünüldüğünde aynı tork değeri için motorların sarım sayısının ne olması gerektiği analitik olarak ya da SEA kullanilarak hesaplanabilir. Yapilan hesaplamalarda Tip A ve Tip B 12/8 KARM için sarım sayıları kutup başına sırasıyla 48 ve 45 olarak elde edilirken Tip A ve Tip B 18/12 KARM için sarım sayıları kutup başına sırasıyla 33 ve 31 şeklindedir. Hesaplanan bu değerlere göre tork ve stator kutbu akı yoğunluğu profilleri sırasıyla Şekil 9 ve 10'da gösterilmiştir. Şekil 10'da görüldügü üzere ÇARM'lerin manyetik akı yoğunluğu profilleri ilgili MMK için doyum bölgesi civarındadır ve benzer tork profillerine sahip KARM'ler ile kıyaslandığında daha yüksek akı yoğunluğu değerleri görülmektedir.

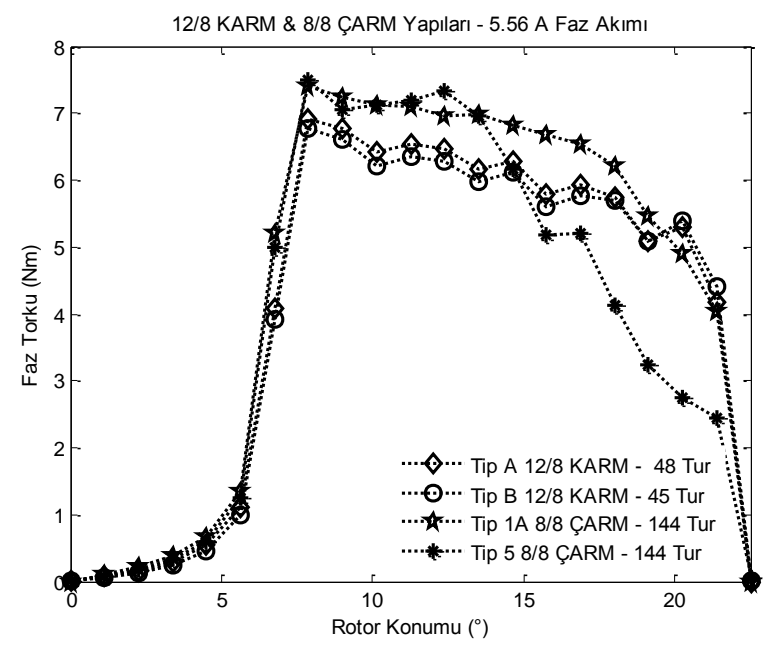

Şekil 9. Benzer tork profiline sahip farklı 12/8 KARM ve 8/8 ÇARM'ler için rotor konumuna karşıllk faz torku (Phase Torque versus rotor position for various 12/8 CSRMs and 8/8 TSRMs with similar torque profiles) 


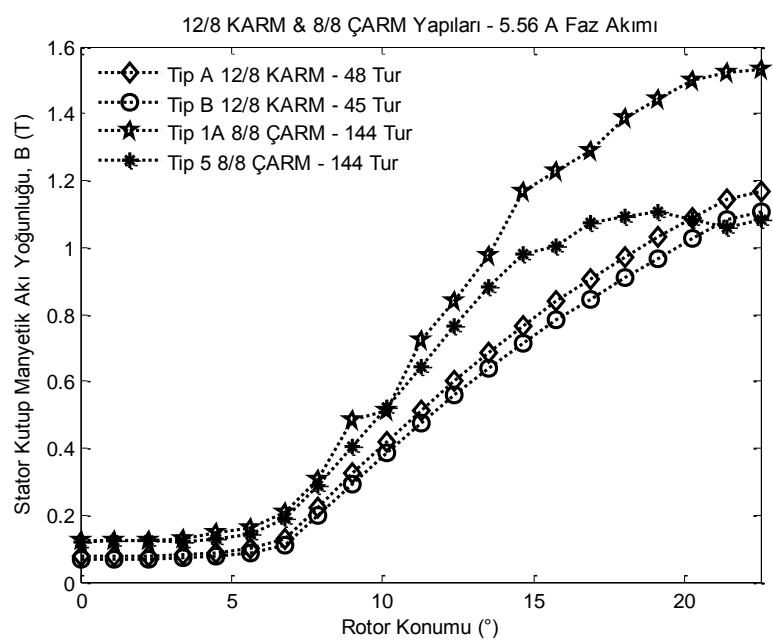

Şekil 10. Benzer tork profiline sahip farklı 12/8 KARM ve 8/8 ÇARM'ler için rotor konumuna karşıllk stator kutbu akl yoğunluğu (Stator pole flux density versus rotor position for various 12/8 CSRMs and 8/8 TSRMs with similar torque profiles)

Şekil 11'de verilen indüktans karakteristiklerine bakıldığında KARM ve ÇARM yapılarının birbirlerine benzer karakteristiklere sahip olduğu ve ilgili akım değeri için indüktanslarının rotor konumuna göre değişiminin neredeyse eşit olduğu görülmektedir. Dolayısıyla KARM'lerin sahip olduğu indüktans profiline bakıldığı zaman ÇARM'lerin sahip olduğu indüktans değişimi oranının sağlanabilmesi için KARM'lerde daha az sarım sayısının yeterli olduğu görülmektedir. Bununla birlikte motorların üretmiş olduğu tork değerleri ve indüktans değişiminin benzer olarak elde edilebilmesi için KARM'lerin eksenel boylarının azaltılabilmesi de mümkündür. Bu durum tork ve indüktans karakteristikleri için sırasıyla Şekil 12 (a) ve (b)'de gösterilmiştir.

Tüm 8/8 ve 12/12 ÇARM yapılarına ait tork yoğunluğu değerleri ile bazı farklılıklar sırasıyla Tablo 3 ve 4'te gösterilmiştir. İlgili tablolar incelendiği zaman tork üretebilme kabiliyeti açısından en uygun yapıların Tip 1A ve Tip 1B ÇARM yapıları olduğu görülmektedir. Buna karşın gerçekleştirilebilme uygunluğu açısından en uygun yapı olan Tip 5 ÇARM'nin diğer tüm ÇARM'lerden yaklaşık iki kata varan daha yüksek birim sargı başına tork üretebilme avantajına sahip olduğu görülmektedir.

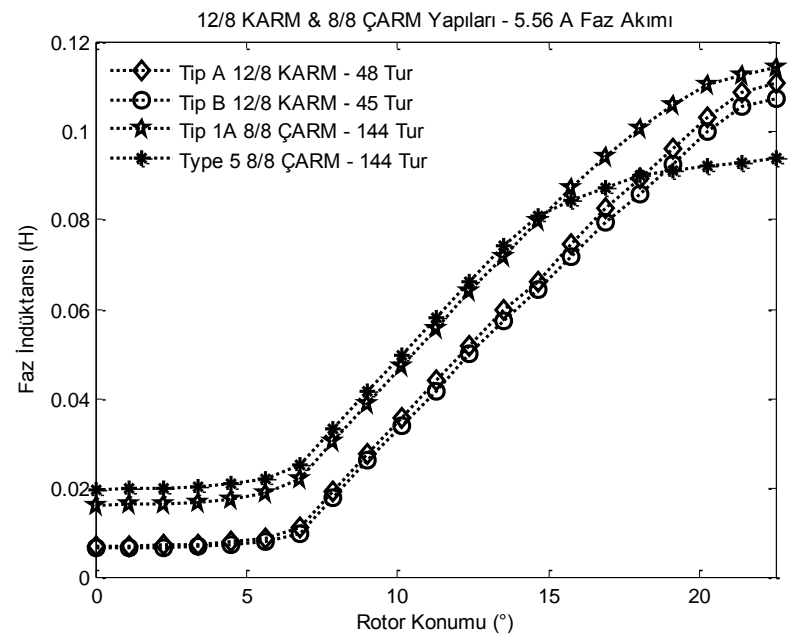

Şekil 11. Benzer faz indüktansı profiline sahip farklı 12/8 KARM ve 8/8 ÇARM'ler için rotor konumuna karşllı faz indüktansı (Phase Inductance versus rotor position for various12/8 CSRMs and 8/8 TSRMs with similar inductance profiles) 


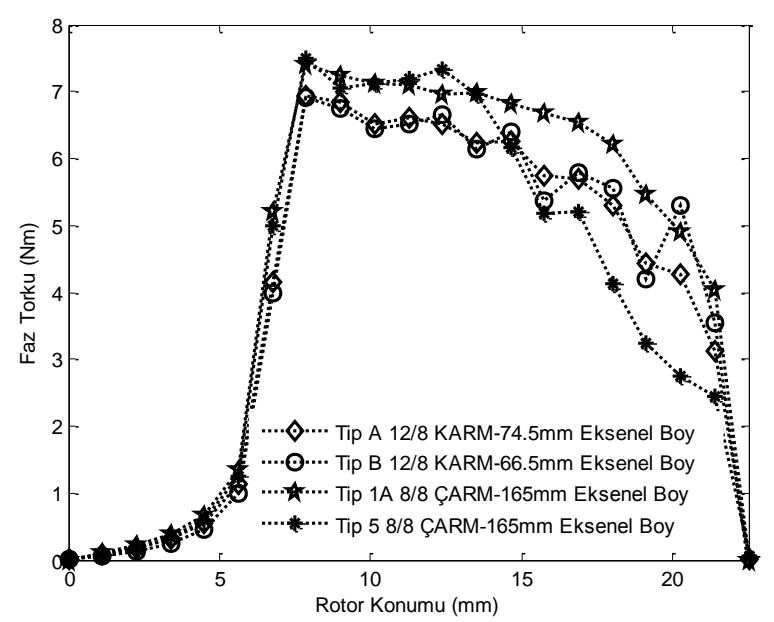

(a)

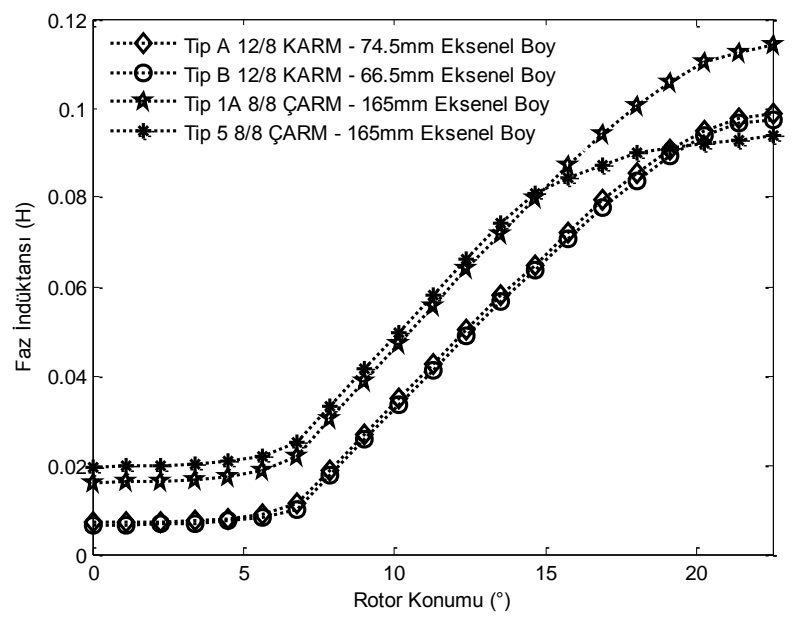

(b)

Şekil 12. Farklı eksenel boylar için (a) faz torku, (b) faz indüktansı profilleri ((a) Phase Torque and (b) inductance versus rotor position for different stack lengths) 
Tablo 3. Tüm 8/8 ÇARM çeşitleri arasındaki farklllkklar (Differences between all types of $8 / 8$ TSRMs)

\begin{tabular}{|c|c|c|c|c|c|c|c|c|c|}
\hline \multirow{2}{*}{$\begin{array}{c}\text { Motor Çeşidi } \\
\text { Özellikler }\end{array}$} & \multicolumn{9}{|c|}{ "8/8 ÇARM } \\
\hline & Tip 1A & Tip 1B & Tip 2A & Tip 2B & Tip 3A & Tip 3B & Tip 4A & Tip 4B & Tip 5 \\
\hline $\begin{array}{l}\text { Ortalama Tork } \\
(\mathrm{Nm})\end{array}$ & 5,78 & 6,01 & 5,76 & 5,89 & 5,64 & 5,88 & 5,50 & 5,80 & 5,11 \\
\hline $\begin{array}{l}\text { Faz Akımı } \\
\text { (A) }\end{array}$ & 5,56 & 5,56 & 5,56 & 5,56 & 5,56 & 5,56 & 5,56 & 5,56 & 5,56 \\
\hline $\begin{array}{l}\text { Kutup Başına Sarım Sayısı } \\
\text { (Tur) }\end{array}$ & 144 & 144 & 144 & 144 & 144 & 144 & 288 & 288 & 144 \\
\hline $\begin{array}{l}\text { Aktif Stator Saç Hacmi } \\
\left(\mathrm{m}^{3}\right)\end{array}$ & $6,44 \mathrm{e}-4$ & $6,44 \mathrm{e}-4$ & $6,44 \mathrm{e}-4$ & $6,44 \mathrm{e}-4$ & $5,83 \mathrm{e}-4$ & $5,83 \mathrm{e}-4$ & $5,83 \mathrm{e}-4$ & $5,83 \mathrm{e}-4$ & $2,53 \mathrm{e}-4$ \\
\hline $\begin{array}{l}\text { Aktif Rotor Saç Hacmi } \\
\left(\mathrm{m}^{3}\right)\end{array}$ & $6,56 \mathrm{e}-4$ & $4,86 \mathrm{e}-4$ & $6,56 \mathrm{e}-4$ & $4,86 \mathrm{e}-4$ & $5,90 \mathrm{e}-4$ & $2,48 \mathrm{e}-4$ & $5,90 \mathrm{e}-4$ & $2,48 \mathrm{e}-4$ & $1,87 \mathrm{e}-4$ \\
\hline $\begin{array}{l}\text { Sargi (Bakır) Hacmi } \\
\left(\mathrm{m}^{3}\right)\end{array}$ & $1,93 \mathrm{e}-4$ & $1,93 \mathrm{e}-4$ & $3,27 \mathrm{e}-4$ & $3,27 \mathrm{e}-4$ & $2,94 \mathrm{e}-4$ & $2,94 \mathrm{e}-4$ & $4,13 \mathrm{e}-4$ & $4,13 \mathrm{e}-4$ & $1,93 \mathrm{e}-4$ \\
\hline $\begin{array}{l}\text { Aktif Stator Saç Ağırlığ } \\
(\mathrm{kg})\end{array}$ & 5,76 & 5,76 & 5,76 & 5,76 & 5,22 & 5,22 & 5,22 & 5,22 & 2,27 \\
\hline $\begin{array}{l}\text { Aktif Rotor Saç Ağırlığ } 1 \\
(\mathrm{~kg})\end{array}$ & 5,87 & 4,35 & 5,87 & 4,35 & 5,28 & 2,22 & 5,28 & 2,22 & 1,68 \\
\hline $\begin{array}{l}\text { Sargi (Bakır) Ağırlığ } \\
(\mathrm{kg})\end{array}$ & 1,73 & 1,73 & 2,93 & 2,93 & 2,63 & 2,63 & 3,7 & 3,7 & 1,73 \\
\hline $\begin{array}{l}\text { Aktif Motor Ağırlığ } \\
(\mathrm{kg})\end{array}$ & 13,36 & 11,84 & 14,56 & 13,04 & 13,13 & 10,07 & 14,20 & 11,14 & 31,20 \\
\hline $\begin{array}{l}\text { Birim Sarg1 Hacmi Başına Tork } \\
\left(\mathrm{Nm} / \mathrm{m}^{3}\right)\end{array}$ & 29948 & 31140 & 17615 & 18012 & 19184 & 20000 & 13317 & 14044 & 26477 \\
\hline $\begin{array}{l}\text { Birim Sarg1 Ağırlığ } 1 \text { Başına } \\
\text { Tork }(\mathrm{Nm} / \mathrm{kg})\end{array}$ & 3,34 & 3,47 & 1,97 & 2,01 & 2,14 & 2,24 & 1,49 & 1,57 & 2,95 \\
\hline $\begin{array}{l}\text { Aktif Motor Ağırlığı Başına } \\
\text { Tork }(\mathrm{Nm} / \mathrm{kg})\end{array}$ & 0,43 & 0,51 & 0,40 & 0,45 & 0,43 & 0,58 & 0,39 & 0,52 & 0,16 \\
\hline
\end{tabular}

Tablo 4. Tüm 12/12 ÇARM çeşitleri arasindaki farkllliklar (Differences between all types of 12/12 TSRMs)

\begin{tabular}{|c|c|c|c|c|c|c|c|c|c|}
\hline \multirow{2}{*}{$\begin{array}{c}\text { Motor Çeşidi } \\
\text { Özellikler }\end{array}$} & \multicolumn{9}{|c|}{ 12/12 ÇARM } \\
\hline & Tip 1A & Tip 1B & Tip 2A & Tip 2B & Tip 3A & Tip 3B & Tip 4A & Tip 4B & Tip 5 \\
\hline $\begin{array}{l}\text { Ortalama Tork } \\
(\mathrm{Nm})\end{array}$ & 9,15 & 9,44 & 9,00 & 9,17 & 8,94 & 9,28 & 8,87 & 9,24 & 8,84 \\
\hline $\begin{array}{l}\text { Faz Akımı } \\
\text { (A) }\end{array}$ & 5,56 & 5,56 & 5,56 & 5,56 & 5,56 & 5,56 & 5,56 & 5,56 & 5,56 \\
\hline $\begin{array}{l}\text { Kutup Başına Sarım Sayısı } \\
\text { (Tur) }\end{array}$ & 144 & 144 & 144 & 144 & 144 & 144 & 288 & 288 & 144 \\
\hline $\begin{array}{l}\text { Aktif Stator Saç Hacmi } \\
\left(\mathrm{m}^{3}\right)\end{array}$ & $6,44 \mathrm{e}-4$ & $6,44 \mathrm{e}-4$ & $6,44 \mathrm{e}-4$ & $6,44 \mathrm{e}-4$ & $5,83 \mathrm{e}-4$ & $5,83 \mathrm{e}-4$ & $5,83 \mathrm{e}-4$ & $5,83 \mathrm{e}-4$ & $2,53 \mathrm{e}-4$ \\
\hline $\begin{array}{l}\text { Aktif Rotor Saç Hacmi } \\
\left(\mathrm{m}^{3}\right)\end{array}$ & $6,56 \mathrm{e}-4$ & $4,86 \mathrm{e}-4$ & $6,56 \mathrm{e}-4$ & $4,86 \mathrm{e}-4$ & $5,90 \mathrm{e}-4$ & $2,48 \mathrm{e}-4$ & $5,90 \mathrm{e}-4$ & $2,48 \mathrm{e}-4$ & $1,87 \mathrm{e}-4$ \\
\hline $\begin{array}{l}\text { Sarg1 (Bakır) Hacmi } \\
\left(\mathrm{m}^{3}\right)\end{array}$ & $1,93 \mathrm{e}-4$ & $1,93 \mathrm{e}-4$ & $3,27 \mathrm{e}-4$ & $3,27 \mathrm{e}-4$ & $2,94 \mathrm{e}-4$ & $2,94 \mathrm{e}-4$ & $4,13 e-4$ & $4,13 \mathrm{e}-4$ & $1,93 \mathrm{e}-4$ \\
\hline $\begin{array}{l}\text { Aktif Stator Saç Ağılığ } 1 \\
(\mathrm{~kg})\end{array}$ & 5,76 & 5,76 & 5,76 & 5,76 & 5,22 & 5,22 & 5,22 & 5,22 & 2,27 \\
\hline $\begin{array}{l}\text { Aktif Rotor Saç Ağırlığ } 1 \\
(\mathrm{~kg})\end{array}$ & 5,87 & 4,35 & 5,87 & 4,35 & 5,28 & 2,22 & 5,28 & 2,22 & 1,68 \\
\hline $\begin{array}{l}\text { Sargı (Bakır) Ağırlığ } 1 \\
(\mathrm{~kg})\end{array}$ & 1,73 & 1,73 & 3,84 & 3,84 & 3,66 & 3,66 & 3,7 & 3,7 & 1,73 \\
\hline $\begin{array}{l}\text { Aktif Motor Ağırlığ } \\
(\mathrm{kg})\end{array}$ & 13,36 & 11,84 & 15,47 & 13,95 & 14,16 & 11,10 & 14,20 & 11,14 & 31,20 \\
\hline $\begin{array}{l}\text { Birim Sarg1 Hacmi Başına } \\
\text { Tork }\left(\mathrm{Nm} / \mathrm{m}^{3}\right)\end{array}$ & 47409 & 48912 & 27523 & 28043 & 30408 & 31565 & 21477 & 22373 & 45803 \\
\hline $\begin{array}{l}\text { Birim Sarg1 Ağırlığ } 1 \text { Başına } \\
\text { Tork }(\mathrm{Nm} / \mathrm{kg})\end{array}$ & 5,29 & 5,46 & 2,34 & 2,39 & 2,44 & 2,54 & 2,40 & 2,50 & 5,11 \\
\hline $\begin{array}{l}\text { Aktif Motor Ağırlığ } 1 \text { Başına } \\
\text { Tork }(\mathrm{Nm} / \mathrm{kg})\end{array}$ & 0,68 & 0,80 & 0,58 & 0,66 & 0,63 & 0,84 & 0,62 & 0,83 & 0,28 \\
\hline
\end{tabular}


Tablo 5'te benzer tork karakteristiğine ve aynı eksenel boya sahip olan 12/8 KARM çeşitleri ile 8/8 Tip 1A ve Tip 5 ÇARM yapıları arasındaki yapısal farklılıklar verilmiştir. Aynı farklılıklar 18/12 KARM çeşitleri ile 12/12 Tip 1A ve Tip 5 ÇARM yapıları için ise Tablo 6'da sunulmuştur. Tablo 5 ve 6 incelendiğinde Tip 1A ÇARM yapısının Tip A KARM ile kıyaslandığı zaman motor ağırlığı dikkate alındığında \% 30 daha yüksek tork yoğunluğuna sahip olduğu görülmektedir. Bununla birlikte endüstriyel uygulamalar açısından endüstriyel cihazların hacimleri çok daha önem arz ettiğinden motor hacmi temel alınarak bir karşılaştırma yapıldığında Tip A KARM, Tip 1A ÇARM ile kıyaslanacak olursa yaklaşı olarak \% 25 daha yüksek tork yoğunluğuna sahiptir. Dolayısıyla bu açıdan değerlendirildiğinde tüm motor yapıları içerisinde Tip A KARM yapılarının avantajlı olduğu söylenebilir.

Tablo 5. 5.56A faz akımı için 12/8 KARM ile 8/8 ÇARM yapıları arasında karşılaştırma (Comparison between 12/8 CSRMs and 8/8 TSRMs for 5.56A phase current)

\begin{tabular}{|c|c|c|c|c|}
\hline \multirow{2}{*}{$\begin{array}{c}\text { Motor Çeşidi } \\
\text { Özellikler }\end{array}$} & \multicolumn{2}{|c|}{$\begin{array}{c}12 / 8 \\
\text { KARM }\end{array}$} & \multicolumn{2}{|c|}{$\begin{array}{c}8 / 8 \\
\text { ÇARM }\end{array}$} \\
\hline & Tip A & Tip B & Tip 1A & Tip 5 \\
\hline Faz Akımı (A) & $\overline{5,56}$ & $\overline{5,56}$ & $\overline{5,56}$ & 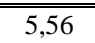 \\
\hline Faz Başına Sarım Sayısı (Tur) & 192 & 180 & 144 & 144 \\
\hline Stator Hacmi $\left(\mathrm{m}^{3}\right)$ & $1,12 \mathrm{e}-3$ & $1,28 \mathrm{e}-3$ & $6,44 \mathrm{e}-4$ & $2,53 \mathrm{e}-4$ \\
\hline Rotor $\mathrm{Hacmi}\left(\mathrm{m}^{3}\right)$ & $1,72 \mathrm{e}-3$ & $2,21 \mathrm{e}-3$ & $6,56 \mathrm{e}-4$ & $1,87 \mathrm{e}-4$ \\
\hline Stator Tozlandırılmıs Demir Malzeme Hacmi $\left(\mathrm{m}^{3}\right)$ & & & & $1,38 \mathrm{e}-3$ \\
\hline Rotor Tozlandırılmıs Demir Malzeme Hacmi $\left(\mathrm{m}^{3}\right)$ & & & & $1,47 \mathrm{e}-3$ \\
\hline Stator Tutucu Hacmi $\left(\mathrm{m}^{3}\right)$ & & & $1,65 \mathrm{e}-3$ & \\
\hline Rotor Tutucu Hacmi $\left(\mathrm{m}^{3}\right)$ & & & $0,93 \mathrm{e}-3$ & \\
\hline Stator Ağırlığ $1(\mathrm{~kg})$ & 10,02 & 11,46 & 5,76 & 2,27 \\
\hline Rotor Ağıllığ $1(\mathrm{~kg})$ & 15,39 & 19,78 & 5,87 & 1,68 \\
\hline Stator Tozlandırılmış Demir Malzeme Ağırlı̆̆ 1 (kg) & & & & 12,38 \\
\hline Rotor Tozlandırılmış Demir Malzeme Ağırlığı $(\mathrm{kg})$ & & & & 13,14 \\
\hline Stator Tutucu Ağırlı ğ $1(\mathrm{~kg})$ & & & 4,45 & \\
\hline Rotor Tutucu Ağırlı̆̆ $1(\mathrm{~kg})$ & & & 2,51 & \\
\hline Sarg1 Ağırlığ $1(\mathrm{~kg})$ & 2,05 & 2,02 & 1,73 & 1,73 \\
\hline Motor Hacmi $\left(\mathrm{m}^{3}\right)$ & $3,07 \mathrm{e}-3$ & $3,71 \mathrm{e}-3$ & $4,07 \mathrm{e}-3$ & $3,48 \mathrm{e}-3$ \\
\hline Motor Ağırlığı (kg) & 27,46 & 33,26 & 20,32 & 31,2 \\
\hline Aktif Motor Hacmi (m³) & $3,07 \mathrm{e}-3$ & $3,71 \mathrm{e}-3$ & $1,49 \mathrm{e}-3$ & $3,48 \mathrm{e}-3$ \\
\hline Aktif Motor Ağırlığı (kg) & 27,46 & 33,26 & 13,36 & 31,2 \\
\hline Ortalama Tork $(\mathrm{Nm})$ & 5,27 & 5,15 & 5,78 & 5,11 \\
\hline Birim Motor Hacmi Başına Tork $\left(\mathrm{Nm} / \mathrm{m}^{3}\right)$ & 1717 & 1388 & 1420 & 1468 \\
\hline Birim Motor Ağırlığ 1 Başına Tork ( $\mathrm{Nm} / \mathrm{kg}$ ) & 0,192 & 0,155 & 0,284 & 0,164 \\
\hline Aktif Motor Hacmi Başına Tork $\left(\mathrm{Nm} / \mathrm{m}^{3}\right)$ & 1717 & 1388 & 3879 & 1468 \\
\hline Aktif Motor Ağırlığ 1 Başına Tork (Nm/kg) & 0,192 & 0,155 & 0,433 & 0,164 \\
\hline
\end{tabular}


Tablo 6. 8 A faz akımı için 18/12 KARM ile 12/12 ÇARM yapıları arasında karşılaştırma (Comparison between 18/12 CSRMs and 12/12 TSRMs for 8A phase current)

\begin{tabular}{|c|c|c|c|c|}
\hline \multirow{2}{*}{$\begin{array}{l}\text { Motor Çeşidi } \\
\text { Özellikler }\end{array}$} & \multicolumn{2}{|c|}{$\begin{array}{c}18 / 12 \\
\text { KARM }\end{array}$} & \multicolumn{2}{|c|}{$\begin{array}{c}12 / 12 \\
\text { ÇARM }\end{array}$} \\
\hline & Tip A & Tip B & Tip $1 \mathrm{~A}$ & Tip 5 \\
\hline Faz Akımı (A) & 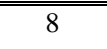 & 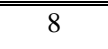 & 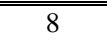 & 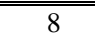 \\
\hline Faz Başına Sarım Sayısı (Tur) & 198 & 186 & 100 & 100 \\
\hline Stator Hacmi $\left(\mathrm{m}^{3}\right)$ & $1,12 \mathrm{e}-3$ & $1,28 \mathrm{e}-3$ & $6,44 \mathrm{e}-4$ & $2,53 \mathrm{e}-4$ \\
\hline Rotor Hacmi $\left(\mathrm{m}^{3}\right)$ & $1,72 \mathrm{e}-3$ & $2,21 \mathrm{e}-3$ & $6,56 \mathrm{e}-4$ & $1,87 \mathrm{e}-4$ \\
\hline Stator Tozlandırılmış Demir Malzeme Hacmi $\left(\mathrm{m}^{3}\right)$ & & & & $1,38 \mathrm{e}-3$ \\
\hline Rotor Tozlandırılmış Demir Malzeme Hacmi $\left(\mathrm{m}^{3}\right)$ & & & & $1,47 \mathrm{e}-3$ \\
\hline Stator Tutucu Hacmi $\left(\mathrm{m}^{3}\right)$ & & & $1,65 \mathrm{e}-3$ & \\
\hline Rotor Tutucu Hacmi $\left(\mathrm{m}^{3}\right)$ & & & $0,93 \mathrm{e}-3$ & \\
\hline Stator Ağıllı̆g $1(\mathrm{~kg})$ & 10,02 & 11,46 & 5,76 & 2,27 \\
\hline Rotor Ağırllğ $1(\mathrm{~kg})$ & 15,39 & 19,78 & 5,87 & 1,68 \\
\hline Stator Tozlandırılmış Demir Malzeme Ağırlığ 1 (kg) & & & & 12,38 \\
\hline Rotor Tozlandırılmış Demir Malzeme Ağırlığ (kg) & & & & 13,14 \\
\hline Stator Tutucu Ağıllı̆ı $1(\mathrm{~kg})$ & & & 4,45 & \\
\hline Rotor Tutucu Ağırlığ $1(\mathrm{~kg})$ & & & 2,51 & \\
\hline Sarg1 Ağırlı̆̆ı (kg) & 2,03 & 1,94 & 1,19 & 1,19 \\
\hline Motor Hacmi $\left(\mathrm{m}^{3}\right)$ & $3,07 \mathrm{e}-3$ & $3,71 \mathrm{e}-3$ & $4,01 \mathrm{e}-3$ & $3,41 \mathrm{e}-3$ \\
\hline Motor Ağırlığ $1(\mathrm{~kg})$ & 27,44 & 33,18 & 19,78 & 30,66 \\
\hline Aktif Motor Hacmi $\left(\mathrm{m}^{3}\right)$ & $3,07 \mathrm{e}-3$ & $3,71 \mathrm{e}-3$ & $1,43 \mathrm{e}-3$ & $3,41 \mathrm{e}-3$ \\
\hline Aktif Motor Ağırlığ 1 (kg) & 27,44 & 33,18 & 12,82 & 30,66 \\
\hline Ortalama Tork $(\mathrm{Nm})$ & 9,00 & 8,87 & 9,15 & 8,84 \\
\hline Birim Motor Hacmi Başına Tork $\left(\mathrm{Nm} / \mathrm{m}^{3}\right)$ & 2932 & 2391 & 2282 & 2592 \\
\hline Birim Motor Ağırlığı Başına Tork (Nm/kg) & 0,328 & 0,267 & 0,463 & 0,288 \\
\hline Aktif Motor Hacmi Başına Tork $\left(\mathrm{Nm} / \mathrm{m}^{3}\right.$ & 2932 & 2391 & 6399 & 2592 \\
\hline Aktif Motor Ağırlığı Başına Tork (Nm/kg) & 0,328 & 0,267 & 0,714 & 0,288 \\
\hline
\end{tabular}

\section{FİIIKSEL YAPILANDIRMA ZORLUKLARI (PHYSICAL ASSEMBLY DIFFICULTIES)}

Tip 5 ÇARM'nin üretiminde saç plakalarının yerleşimi klasik yapıdaki ARM'lerinkine oldukça benzer olduğu için Tip 5 ÇARM, diğer tüm ÇARM yapıları içerisinde en kolay üretilebilme avantajına sahiptir. Dolayısıyla Tip 5 ÇARM yapısının, KARM yapısı ile bazı ortak mekaniksel özelliklere sahip olduğu söylenebilir. Bununla birlikte akının eksenel olarak dolaşabilmesi için stator ve rotor tozlandırılmış demir malzemelerin kullanılma zorunluluğu bu yapının KARM'lerle en büyük farklılığıdır. Aynı zamanda, Tip 5 ÇARM'de iki farklı manyetik özelliğe sahip motor yapısı birlikte kullanıldığından, bu yapıların olası ek relüktansların ve kaçak akıların açığa çıkmasının önüne geçilebilmesi adına çok iyi bir şekilde yerleştirilmesi gerektiği unutulmamalıdır.

Diğer ÇARM yapıları için ise çok sayıda rotor ve stator parçasının bir arada ve uygun şekilde tutulabilmesi için özel mekaniksel aksamlara gereksinim duyulmaktadır. Bu durum, artan üretim maliyeti dışında birçok üretim süreci ve zorluğunu da beraberinde getirmektedir. Dolayısıyla ancak sınırlı bir güç aralığında (< 25hp) bu tip motorların gerçekleştirimi mümkün iken daha yüksek güçlerde KARM'lere kıyasla çok daha fazla üretim sorunlarıyla karşılaşılması olasıdır.

Sonuç olarak tüm ÇARM'ler için KARM'ler ile kıyaslandığında daha fazla mekaniksel aksamlara ve üretim süreçlerine gereksinim duyulmakta olup bu durum da ek üretim maliyetlerini beraberinde getirmektedir. 


\section{SONUÇLAR (CONCLUSIONS)}

Bu çalışmada, radyal akı dağılımına sahip klasik ARM'ler ile farklı yapıdaki çapraz akı dağılımına sahip ARM'ler arasında kapsamlı bir karşılaştırma yapılmıştır. Çok sayıda ARM yapısı, analitik ve nümerik metotların kullanılması suretiyle analiz edilmiştir. Yapılan analiz çalışmalarında literatürde yer alan neredeyse tüm ÇARM yapıları dikkate alınmış ve bu yapıların gerek KARM yapıları ile gerekse de kendi aralarında karşılaştırılabilmesine olanak sağlanmıştır. Gerek motor boyutları gerekse de maksimum akı yoğunluğu ve ortalama tork değerleri temel alınarak yapılan çalışmalarda genel olarak KARM yapılarının birçok açıdan daha avantajlı oldukları elde edilen sonuçlarda gösterilmiştir. Analizler sonunda elde edilen sonuçlar ve mekaniksel hususlar dikkate alındığında klasik radyal akı dağılımına sahip ARM'lerin çapraz akı dağılımına sahip ARM'ler ile karşılaştırıldığında daha tercih edilebilir seçenekler olduğu görülmektedir.

\section{SEMBOLLER (SYMBOLS)}

$\begin{array}{ll}A_{s} & \text { Stator Kutup Kesit Alanı } \\ l_{s} & \text { Stator Kutup Uzunluğu } \\ w_{s} & \text { Stator Kutup Genişliği } \\ A_{s p i} & \text { Stator Tozlandırılmış Demir Malzeme Etkin Kesit Alan } \\ l_{s p i} & \text { Stator Kutbu için Stator Tozlandırılmış Demir Malzeme Kalınlığı } \\ w_{s p i} & \text { Stator Kutbu için Stator Tozlandırılmış Demir Malzeme Genişliği } \\ \phi_{s} & \text { Stator Saç Plakası Manyetik Akısı } \\ \phi_{s p i} & \text { Stator Tozlandırılmış Demir Malzeme Manyetik Akısı } \\ \phi & \text { Manyetik Akı } \\ B & \text { Manyetik Akı Yoğunluğu } \\ A & \text { Etkin Kesit Alan } \\ B_{s} & \text { Stator Saç Plaka Manyetik Akı Yoğunluğu } \\ B_{s p i} & \text { Stator Tozlandırılmış Demir Malzeme Manyetik Akı Yoğunluğu } \\ k_{s} & \text { Stator Tozlandırılmış Demir Malzeme Sabiti } \\ r_{s p i} & \text { Statora Ait Tozlandırılmış Demir Malzemenin Yarıçapı } \\ B_{r} & \text { Rotor Saç Plaka Manyetik Akı Yoğunluğu } \\ B_{r p i} & \text { Stator Tozlandırılmış Demir Malzeme Manyetik Akı Yoğunluğu } \\ l_{r} & \text { Rotor Kutbunun Eksenel Boyu } \\ k_{r} & \text { Rotor Tozlandırılmış Demir Malzeme Sabiti } \\ r_{s h} & \text { Şaft Yarıçapı } \\ r_{r p i} & \text { Rotora Ait Tozlandırılmış Demir Malzemenin Yarıçapı } \\ T_{e} & \text { Elektromanyetik Tork } \\ W^{\prime} & \text { Ko-enerji } \\ \lambda & \text { Halkalanma Akısı } \\ i & \text { Akım } \\ \mathrm{L}_{\mathrm{a}} & \text { Çakışık Konumdaki İndüktans } \\ & \end{array}$




$\begin{array}{ll}P_{s} & \text { Stator Kutup Sayısı } \\ q & \text { Faz Sayısı } \\ N & \text { Kutup Başına Sarım Sayısı } \\ l_{g} & \text { Hava Aralığı } \\ \mu_{0} & \text { Hava Aralığı Manyetik Geçirgenliği } \\ \mathfrak{R} & \text { Relüktans } \\ \theta_{a} & \text { Radyan Cinsinden Çakışık Rotor Konumu } \\ \theta_{u} & \text { Radyan Cinsinden Ortalanmış Rotor Konumu } \\ P_{r} & \text { Rotor Kutup Sayısı } \\ T_{e c} & \text { KARM' ye ait Elektromanyetik Tork } \\ T_{e t} & \text { ÇARM' ye ait Elektromanyetik Tork }\end{array}$

\section{TEŞEKKÜR (ACKNOWLEDGMENTS)}

N. Üstkoyuncu, Virginia Tech'de doktora sonrası çalışmalarda bulunmak üzere kendisine finansal destek sağlayan KCETAŞ'a teşekkür eder.

\section{KAYNAKLAR (REFERENCES)}

[1] Krishnan R., Switched Reluctance Motor Drives: Modeling, Simulation, Analysis, Design and Applications, CRC Press, New York, A.B.D, 2001.

[2] Krishnan R., An energy-efficiency-enhanced switched reluctance motor [from mind to market], IEEE Industrial Electronics Magazine, 1 (1), 4-6, 2007.

[3] Oh S.G., Krishnan R., Two-phase SRM with flux-reversal-free stator: concept, analysis, design and experimental verification, IEEE Transactions on Industry Applications, 43 (5), 1247-1257, 2007.

[4] Daldaban F., Ustkoyuncu N., Multi-layer switched reluctance motor to reduce torque ripple, Energy Conversion and Management, 49 (5), 974-979, 2008.

[5] Lee C., Krishnan R., Lobo N.S., Novel two-phase switched reluctance machine using common-pole E-core structure: concept, analysis and experimental verification, IEEE Transactions on Industry Applications, 45 (2), 703-711, 2009.

[6] Lee C., Krishnan R., New designs of a two-phase E-core switched reluctance machine by optimizing the magnetic structure for a specific application: concept, design, and analysis, IEEE Transactions on Industry Applications, 45 (5), 1804-1814, 2009.

[7] Kim J., Ha K., Krishnan R., Single-controllable-switch-based switched reluctance motor drive for low cost variable-speed applications, IEEE Transactions on Power Electronics, 27 (1), 379-387, 2012.

[8] Vattikuti N., Vandana R., Fernandes B.G., A novel high force density linear segmented switched reluctance machine, $34^{\text {th }}$ Annual Conference of IEEE Industrial Electronics - IECON, 1083-1088, 1013 November 2008.

[9] Sui-chun Q., Hua-bo L., Xiao-guang M., A design of transverse flux switched reluctance motors with permanent magnet shield, International Conference on Electrical Machines and Systems - ICEMS, 3367-3369, 17-20 October 2008.

[10] Baoming G., De Almeida A.T., Ferreira F., Design of transverse flux linear switched reluctance motor, IEEE Transactions on Magnetics, 45 (1), 113-119, 2009. 
[11] Zula A., Mecrow B.C., Armstrong M., A wound-field three-phase flux-switching synchronous motor with all excitation sources on stator, IEEE Transactions on Industry Applications, 46 (6), 2363-2371, 2010.

[12] Song U., You Y., Kwon B., Design and analysis of transverse flux switched reluctance generators for wind turbine, $14^{\text {th }}$ Biennial IEEE Conference on Electromagnetic Fiels Computation - CEFC, 9-12 May 2010.

[13] Darabi S., Beromi Y.A., Izadfar H.R., Comparison of two common configurations of LSRM: Transverse flux and longitudinal flux, International Conference and Exposition on Electrical and Power Engineering - EPE, 451-455, 25-27 October 2012.

[14] Li Y., Li H., Li Z., Design and implement of novel transverse flux switched reluctance magnetic energy motor combined with control system, International Conference on Mechatronics and Automation - ICMA, 1675-1680, 4-7 August 2013.

[15] Gundogan Turker C., Çınar M.A., Erfan Kuyumcu F., Analysis of the E-core transverse flux machine for indoor training bike application, Journal of the Faculty of Engineering and Architecture of Gazi University, 29 (1), 61-69, 2014.

[16] Amreiz H.M., Mecrow B.C., Weiner C., Linde A.G., Switched reluctance machines with simple hoop windings, International Conference on Power Electronics, Machines and Drives, 522-526, 4-7 June 2002.

[17] Hongquan Y., Chenglin G., Analytical design and modeling of transverse flux switched reluctance machine, International Conference on Electrical Machines and Systems - ICEMS, 3414-3416, 17-20 October 2008.

[18] Amreiz H.M., A comparison between transverse flux and conventional switched reluctance machine, $19^{\text {th }}$ International Conference on Electrical Machines - ICEM, 1-8, 6-8 September 2010.

[19] Vannier J.C., Vidal P., Poirson C., Analysis and control of a reluctance motor having a toroidal magnetic circuit, International Conference on Electrical Machines - ICEM, 119-124, 2-4 September 1998.

[20] Amreiz H.M., Difficulties and complexities encountered in the design of transverse flux machines, Electrical Systems for Aircraft, Railway and Ship Propulsion - ESARS, 1-6, 16-18 October 2012.

[21] Ustkoyuncu N., Krishnan R., A performance comparison of conventional and transverse flux linear switched reluctance motors, Turkish Journal of Electrical Engineering and Computer Sciences, 23 (4), 974-986, 2015. 